\title{
ГРАНИЦЫ ТРАНСПАРЕНТНОСТИ КОРПОРАТИВНЫХ ЗАКУПОК
}

\author{
(c) 2019 Агапова Елена Викторовна
}

кандидат экономических наук, доцент, ведущий научный сотрудник научно-исследовательской лаборатории «Исследования актуальных вопросов развития конкурентной политики и государственного заказа в российской экономике», директор Центра развития конкурентной политики и государственного заказа

Российская академия народного хозяйства и государственной службы при Президенте Российской Федерации, Россия, Москва

E-mail: goszakaz@ranepa.ru

\section{(c) 2019 Беляева Ольга Александровна}

доктор юридических наук, профессор РАН, ведущий научный сотрудник научноисследовательской лаборатории «Исследования актуальных вопросов развития конкурентной политики и государственного заказа в российской экономике»

Центра развития конкурентной политики и государственного заказа

Российская академия народного хозяйства и государственной службы при Президенте Российской Федерации, Россия, Москва

E-mail: goszakaz@ranepa.ru

Сфера публичных закупок в Российской Федерации является значимым сектором отечественной экономики - в области публичных закупок товаров, работ, услуг контрактуется примерно 20 трлн. руб. в год. В центре внимания авторов статьи область закупок, осуществляемых компаниями с государственным участием и организациями, осуществляющими регулируемые виды деятельности.

Авторы обращают внимание на разное понимание открытости закупок: от планирования потребности до ее удовлетворения путем надлежащего выполнения договорных обязательств.

Транспарентность (открытость) закупочного цикла - один из фундаментальных принципов законодательства о закупках. И это неслучайно, поскольку открытость информации идет рука об руку с противодействием коррупции и другим злоупотреблениям при осуществлении закупок. На протяжении последних лет увеличивается функционал Единой информационной системы в сфере закупок, причем на полную мощность она еще не заработала.

Однако информационная открытость имеет и оборотную сторону: она делает заказчика уязвимым в конкурентной среде. Кроме того, авторы ставят главный вопрос о том, насколько существующее регулирование соответствует интересам самих заказчиков в секторе корпоративных закупок.

Ключевые слова: закупки, открытость, реестр, план закупки, отчетность, единая информационная система.

Корпоративные закупки являются весомым сектором российской экономики. Так, по данным Минфина России в 2018 г. общий объем этих закупок составил 16,9 трлн. руб., в качестве заказчиков в единой информационной системе зарегистрировано более 90 тыс. юридических лиц".

В п. 1 ч. 1 ст. 3 Федерального закона от 18.07.2011 г. № 223-Ф3 «О закупках товаров, ра-

бот, услуг отдельными видами юридических лиц» (далее - Закон о закупках) закреплен такой принцип закупки, как информационная открытость. Основная дилемма, как нам представляется, заключается в том, чтобы адекватно установить его сущностное содержание ${ }^{* * *}$. Информационная открытость зачастую интерпретируется как запрет проведения закрытых процедур закупки (якобы они ограничивают

\footnotetext{
" Доклад Минфина России о результатах мониторинга Закона № 223 З за 2018 г. // URL: https://www.minfin.ru/ common/upload/library/2019/02/main/223-FZ_v_2018_godu.pdf (дата обращения: 11.03.2019).

** Критическое отношение к нормативному закреплению принципов закупки неоднократно высказывалось в специальной литературе [1, С. 26; 3, С.254].
} 
конкуренцию)

Сомнения в нарушении требований информационной открытости закупки сформировали минимальную практику проведения закрытых закупочных процедур. А потому нам видится концептуально значимым установить пределы корреляции понятий «информационная открытость закупки» и «открытая /закрытая процедура закупки». На наш взгляд, информационная открытость закупки означает размещение на официальном сайте плана закупок, положения о закупке, извещения, документации о закупке, сведений об изменении договора, отчетности по заключенным договорам. Открытость/ закрытость самой процедуры закупки обуславливается порядком приглашения участников. Следствием объявления открытой процедуры является приглашение к участию в ней неопределенного круга лиц (всех желающих), тогда как на участие в закрытой процедуре могут подать заявки лишь те лица, которые были специально приглашены организатором.

Однако сейчас нам следует констатировать, что закрытые процедуры, по сути, оказались вне закона, поскольку ныне действующая ст. 3.5 Закона о закупках допускает проведения подобных закупках лишь в связи с двумя обстоятельствами: государственная тайна и решения Правительства Российской Федерации.

В текущей регламентации информационного обеспечения закупочной деятельности имеется ряд конфликтных ситуаций. Проанализируем некоторые из них.

1. Полное отсутствие гарантий защиты коммерческой тайны. Закон о закупках пренебрегает гарантиями, предусмотренными Федеральным законом от 29.07.2004 г. № 98-Ф3 «О коммерческой тайне», поскольку действи- тельная или потенциальная ценность информации не является основанием для неразмещения ее в Единой информационной системе. Таким образом, наши корпоративные заказчики не располагают возможностью скрыть ценную информацию от действительных или потенциальных конкурентов, хотя именно неизвестность информации образует серьезное конкурентное преимущество. В этой части Закон о закупках нуждается в дополнении соразмерным правилом о границах раскрытия сведений о закупках, относящихся к коммерческой тайне заказчика.

Думается, что полное исключение таких закупок из-под законодательного воздействия не оправдано по причине возможных злоупотреблений, поскольку определение состава тайной информации - прерогатива единоличного исполнительного органа заказчика**. De lege ferenda уместными видятся следующие варианты:

- размещение документации о закупке в два этапа: анонсом (для всех претендентов) и полностью (для лиц, заключивших соглашение о соблюдении конфиденциальности);

- проведение предварительного отбора претендентов.

2. Планирование закупок. Помимо положения о закупке, извещений, документации и протоколов, корпоративные заказчики обязаны размещать в Единой информационной системе планы ${ }^{* * *}$. Это принципиально важно: договоры на поставку товаров, выполнение работ, оказание услуг заключаются заказчиком в соответствии с планом закупки (ч. 5.1 ст. 3 Закона о закупках). Иными словами, провести закупку по отсутствующей в плане позиции невозможно. Тем самым законодательство «привязывает» фактические закупки к ранее запланированным

\footnotetext{
" См., например, постановление Двадцатого арбитражного апелляционного суда от 10.04.2014 г. по делу № А09-8106/2013, постановление Восемнадцатого арбитражного апелляционного суда от 17.10 .2012 г. № 18АП-9692/2012 по делу № А47-1155/2012.

Кстати, по этому поводу был и еще один интересный прецедент в арбитражной практике. Так, Арбитражный суд Республики Татарстан в решении от 23.04.2013 г. по делу № А65-1633/2013 указал на правомерность проведения заказчиком закрытого конкурса, поскольку это прямо не запрещено законом.

*** В свое время Минэкономразвития России давало разъяснения по данному вопросу в письме от 27.09.2016 г. № Д28и-2610. Они изложены довольно витиевато, но уяснить суть их возможно, она заключается в прогнозе появления неконтролируемых злоупотреблений: «... понятие коммерческой тайны является сложноадминистрируемым и определяется самим заказчиком, в связи с чем существует риск, что заказчики большинство процедур будут выводить из публичной сферы».

*** См. Правила формирования плана закупки товаров (работ, услуг) и требования к форме такого плана, утв. постановлением Правительства РФ от 17.09.2012 г. № 932.
} 
позициям*. Причем в плане закупки должна содержаться детальная информация о закупках, а не об обобщенных потребностях корпоративного заказчика.

Из данного правила, конечно, есть исключения. Во-первых, речь идет о так называемых непубликуемых закупках, информация о которых не вносится в ЕИС. Так, заказчик может не размещать сведения о закупке товаров, работ, услуг, стоимость которых не превышает 100 тыс. руб. В случае если годовая выручка заказчика за отчетный финансовый год составляет более чем 5 млрд. руб., заказчик вправе не размещать в единой информационной системе сведения о закупке товаров, работ, услуг, стоимость которых не превышает 500 тыс. руб.

Разумеется, не должны размещаться в ЕИС сведения об осуществлении закупок товаров, работ, услуг, о заключении договоров, составляющие государственную тайну (ч. 15 ст. 4 Закона о закупках). Кроме того, Правительство РФ наделено полномочиями определить и другие причины для неразмещения информации о закупках:

- конкретную закупку, сведения о которой не составляют государственную тайну, но не подлежат размещению в единой информационной системе;

- перечни и (или) группы товаров, работ, услуг, сведения о закупке которых не составляют государственную тайну, но не подлежат размещению в единой информационной системе;

- перечень оснований неразмещения в единой информационной системе информации о поставщике (подрядчике, исполнителе), с которым заключен договор;

- перечни и (или) группы товаров, работ, услуг, закупки которых осуществляются конкретными заказчиками, сведения о закупке которых не составляют государственную тайну, но не подлежат размещению в единой информационной системе.

Любые закупки в случае аварии, иных чрезвычайных ситуаций природного или техногенного характера, непреодолимой силы, при необходимости срочного медицинского вмешательства, а также для предотвращения угрозы возникновения указанных ситуаций проводятся вне плана.

Но помимо плана закупки, срок действия которого должен быть не менее одного года, корпоративные заказчики обязаны размещать на официальном сайте план закупки инновационной продукции, высокотехнологичной продукции, лекарственных средств на период от 5 до 7 лет. Актуальным является вопрос об обязательности размещения такого плана в случае, если на текущий момент у заказчика нет потребности в приобретении подобной продукции.

Однако Закон о закупках не делает исключений для ситуации, когда такая продукция заказчику не требуется, поэтому многие корпоративные заказчики вынуждены размещать нулевые (бессодержательные) планы.

Еще одна веская причина для размещения нулевого плана - возможность его последующих изменений. Если плана (пусть и нулевого, пустого, не было, то при возникновении в будущем потребности в подобной продукции нечего будет и корректировать. Если же заказчиком был размещен нулевой план, то в него всегда можно внести изменения. Эти нелепица с планированием, конечно, требует корректировки и первым ее направлением должно стать сокращение сроков планирования. Нам представляется целесообразным установить унифицированный период планирования продолжительностью 1 год. Весомым аргументом для сокращения сроков планирования является сама по себе категория «инновационная продукция», даже если составлять план закупки такой продукции на пятилетний период, то за это время она попросту утратит свои инновационные свойства и характеристики.

И вот здесь мы подходим ко второму направлению оптимизации планирования: критериям отнесения товаров, работ, услуг к инновационной продукции и (или) высокотехнологичной продукции для целей формирования плана закупки. Сейчас эти критерии устанавливают федеральные органы исполнительной власти, а также Государственные корпорации «Росатом» и «Роскосмос» с учетом утвержденных Президентом РФ приоритетных направлений развития науки, технологий и техники в Российской Федерации и перечнем критических техноло-

\footnotetext{
" Отметим, что в корпоративных закупках нет моратория на проведение незапланированной закупки, поэтому внесение изменений в план закупки и размещение соответствующего извещения может быть сделано «день в день».
} 
гий Российской Федерации". Надо признать, что критерии эти имеют весьма расплывчатый характер и могут быть применимы к совершенно разным видам продукции, так что разграничить инновационную, высокотехнологичную и обычную продукцию затруднительно **.

Одним словом, унифицированного понимания сущности критериев нет, как нет и ясности в вопросе о том, критериям какого органа власти нужно следовать корпоративному заказчику при формировании соответствующего плана. В связи с этим нам видится необходимым принципиально пересмотреть подходы к установлению подобных критериев: их не должно быть много, заказчикам следует ориентироваться на какой-либо единый источник получения соответствующей информации. Представляется, что выработка критериев должна быть прерогативой Правительства РФ.

Наконец, есть и третье направление корректировки планирования, это неприятный казус, который требует скорейшего устранения. Суть проблемы заключается в следующем.

Согласно ч. 15 ст. 4 Закона № 223-ФЗ заказчик вправе не размещать в ЕИС сведения, перечень которых разделен на 3 пункта (так называемые непубликуемые закупки):

1) закупка товаров, работ, услуг, стоимость которых не превышает 100 тыс. руб. (в случае, если годовая выручка заказчика за отчетный финансовый год составляет более чем 5 млрд. руб.,- до 500 тыс. руб.;

2) закупка услуг по привлечению во вклады (включая размещение депозитных вкладов) денежных средств организаций, получению кредитов и займов, доверительному управлению денежными средствами и иным имуществом, выдаче банковских гарантий и поручительств, предусматривающих исполнение обязательств в денежной форме, открытию и ведению счетов, включая аккредитивы, о закупке брокерских услуг, услуг депозитариев;

3) закупка, связанная с заключением и исполнением договора купли-продажи, аренды (субаренды), договора доверительного управления государственным или муниципальным имуществом, иного договора, предусматривающего переход прав владения и (или) пользования в отношении недвижимого имущества.

Есть ли у заказчика обязанность включать закупки, предусмотренные пунктами 2 и 3 (финансовые услуги, публичное и недвижимое имущество) в план закупки? Нужно ли включать сведения о заключенных в результате таких закупок договорах в реестр договоров?

Сейчас наблюдается определенная коллизия в регулировании данного вопроса. Потому что по логике если речь идет о непубликуемых закупках, то сведений о них не должно быть нигде, в том числе ни в плане, ни в реестре. Однако согласно п. 4 Правил формирования плана закупки товаров (работ, услуг), утв. постановлением Правительства РФ от 17.09.2012 г. № 932, в качестве сведений, которые могут не включаться в план закупки, пункты 2 и 3 цитируемой нормы не указаны. Причина в том, что подзаконные требования к формированию плана закупки не приведены в соответствие с изменившейся редакцией части 15 статьи 4 Закона о закупках. Выходит так, что в план закупки данные сведения не включать нельзя.

Но с реестром договором складывается совершенно другая история: пункт 4 Правил ведения реестра договоров, заключенных заказчиками по результатам закупки, утв. постановлением Правительства РФ от 31.10.2014 г. № 1132, отсылает к части 15 статьи 4 Закона о закупках без уточнений (то есть к норме целиком), следова-

\footnotetext{
"См. указ Президента РФ от 07.07.2011 г. № 899 «Об утверждении приоритетных направлений развития науки, технологий и техники в Российской Федерации и перечня критических технологий Российской Федерации».

*** Так, согласно приказу Минэнерго России от 25.12.2015 г. № 1026, к инновационной продукции и (или) высокотехнологичной продукции для целей формирования плана закупки такой продукции следует относить товары, работы и услуги, соответствующие не менее чем четырем следующим критериям: научно-техническая новизна, экономический эффект реализации товаров, работ, услуг, высокий технический уровень, соответствие приоритетным направлениям развития науки, технологий и техники Российской Федерации и наукоемкость товаров, работ, услуг.

В то же время в соответствии с приказом Минтранса России от 25.08.2015 г. № 261 к высокотехнологичной продукции относятся товары, работы, услуги, удовлетворяющие совокупности следующих критериев: а) товар, работа, услуга изготавливаются, выполняются, оказываются предприятиями наукоемких отраслей экономики; б) товар, работа, услуга производятся, выполняются, оказываются с использованием новейших образцов технологического оборудования, технологических процессов и технологий; в) товар, работа, услуга производятся, выполняются, оказываются с участием высококвалифицированного, специально подготовленного персонала.
} 
тельно, сведения о закупках финансовых услуг и договорах по использования публичного и недвижимого имущества не подлежат включению в реестр договоров.

Таким образом, надлежит как можно скорее привести подзаконное регулирование в соответствие с нормой федерального закона, иначе в планах заказчиков будут постоянно находиться незакрытые закупочные позиции.

3. Отчетность о заключенных договоpax. На основании ч. 19 ст. 4 Закона о закупках каждый корпоративный заказчик обязан в срок не позднее 10-го числа месяца, следующего за отчетным, заполнять на официальном сайте 3 строки отчетности:

- сведения о количестве и об общей стоимости договоров, заключенных заказчиком по результатам закупки товаров, работ, услуг, в том числе об общей стоимости договоров, информация о которых не внесена в реестр договоров;

- сведения о количестве и стоимости договоров, заключенных заказчиком по результатам закупки у единственного поставщика (исполнителя, подрядчика);

- сведения о количестве и стоимости договоров, заключенных заказчиком с единственным поставщиком (исполнителем, подрядчиком) по результатам конкурентной закупки, признанной несостоявшейся.

Это регулирование следует назвать архаизмом, ведь есть реестр договоров, заключенных заказчиками (ст. 4.1 Закона о закупках), в который включается множество сведений и документов, а потому ежемесячная отчетность, не сопровождаемая какими-либо документами, какого-либо значения не имеет. Такая отчетность не дает и не может дать ясного представления о спектре фактических закупок заказчика. Дело в том, что в отличие от реестра договоров в отчетность помещаются сведения только о заключенных договорах. Изменение или расторжение договора содержание отчетности не меняет. Более того, Законом о закупках не легитимировано внесение в данную отчетность изменений. Предположим, в отчетном месяце корпоративный заказчик заключает договор на 100 млн. руб., а в следующем месяце его расторгнуть в связи с объективным исчезновением потребности в соответствующих товарах, работах или услугах. Однако в составе отчетности сум- ма этого договора останется. Или же корпоративный заказчик может заключить договор на определенную, но при этом предельную сумму с условием о выборке товара в зависимости от своих нужд. Даже если фактическая выборка не достигнет 100\% первоначальной цены договора, отчетность не изменится.

Сведения, отображенные в ежемесячной отчетности, никогда не соответствуют фактически заключенным заказчиками договорам, потому как в отчетность включаются договора, заключенные по результатам непубликуемых закупок. То есть в ЕИС этих закупок нет, в реестре их тоже нет, но по первой строке они проходят. Здесь уместно задаться вопросом о проверяемости такой информации, нам представляется сомнительной вероятность установления ее достоверности.

Наконец, с учетом современной классификации способов закупки порядок составления ежемесячной отчетности предлагаем называть «Матрешка» в связи со следующими соображениями.

Все способы закупок имеют градацию на конкурентные и неконкурентные. Неконкурентные - это закупка у единственного поставщика (подрядчика, исполнителя) и иные способы, но какие именно, Закон о закупках не уточняет, отдавая решение этого вопроса на самостоятельное усмотрение заказчиков. Сейчас есть заказчики, которые в качестве неконкурентного способа закупки определили исключительно закупку у единственного поставщика (например, ПАО «НК «Роснефть»), детализировав ее по видам. Допустим, одним из видов такой закупки является заключение договора по итогам победы в конкурентной процедуре продавца. Другие заказчики (например, ПАО «Газпром»), напротив, выделили ровно такую же закупку в качестве «иного способа», не тождественного закупке у единственного поставщика. Оба подхода предписаниям Закона о закупках соответствуют, но по-разному отображаются в составе ежемесячной отчетности: в первом примере сведения о заключенном договоре попадают в строки 1 и 2 ; во втором - только в строку 1. Иными словами, идентичные ситуации в аспекте отчетности общего знаменателя не имеют, что считать приемлемым, по нашему мнению, нельзя*.

Причем норма об отчетности отнюдь не безобидна - ее несоблюдение образует админи-

\footnotetext{
"Можно приводить еще массу других примеров, демонстрируя хаотичность содержания анализируемой отчетности.
} 
стративный состав на основании ч. 5 и 6 ст. 7.32.3 КоАП РФ (если отчетность не заполняется или размещается в ЕИС с нарушением установленного срока [2]. Тем более, что перед нами так называемый формальный состав административного правонарушения, избежать ответственности в этом случае практически невозможно.

Изложенное позволяет нам прийти к выводу о необходимости скорейшего упразднения обязанности корпоративных заказчиков по заполнению ежемесячной отчетности о заключенных договорах.
Подводя итог проведенному исследованию, отметим, что нами затронута проблематика транспарентности лишь в одной сфере публичных закупок и только применительно к ней намечено значительное число сценариев оптимизации законодательного воздействия. В то время как тщательному и критическому исследованию можно подвергнуть и другие закупочные области, а именно сферу контрактной системы и отношения, связанные с реализацией государственного оборонного заказа.

\section{Библиографический список}

1. Актуальные вопросы современного конкурентного права: сб. научных трудов. Выпуск (3) 2019 / отв. ред. М.А. Егорова. М., 2019

2. Беляева О.А. Закупки. Торги. Избранное. М., 2019

3. Конкуренция в рыночной экономике: пределы свободы и ограничений: монография / отв. ред. А.В. Габов. M., 2016 